\title{
Correction to: The Influence of Light Wavelength on Growth and Antioxidant Capacity in Pachyrhizus erosus (L.) Urban
}

\author{
III Min Chung ${ }^{1}$ - Niroj Paudel ${ }^{2}$. Seung-Hyun $\mathrm{Kim}^{1} \cdot$ Chang Yeon $\mathrm{Yu}^{2} \cdot$ Bimal Kumar Ghimire $^{1}$
}

Published online: 13 August 2019

○) Springer Science+Business Media, LLC, part of Springer Nature 2019

\section{Correction to: Journal of Plant Growth Regulation https://doi.org/10.1007/s00344-019-09982-1}

The original version of this article unfortunately contained an error in Acknowledgement. The authors would like to correct the error with this erratum.

The correct sentence should read as:
This paper was supported by the KU Research Professor Program of Konkuk University, Seoul, South Korea.

Publisher's Note Springer Nature remains neutral with regard to jurisdictional claims in published maps and institutional affiliations.

The original article can be found online at https://doi.org/10.1007/ s00344-019-09982-1.

Bimal Kumar Ghimire

bimal_g12@yahoo.com

1 Department of Applied Life Science, Konkuk University, Seoul 05025, Korea

2 Bioherb Research Institute, Kangwon National University, Chuncheon 24341, Korea 